\title{
Excerpt from
}

\section{Personality and Close Relationship Processes ${ }^{1}$}

\author{
Stanley O. Gaines, Jr.
}

Brunel University London

\footnotetext{
${ }^{1}$ This material is scheduled to be published in Personality and Close Relationship Processes by Stanley O. Gaines, Jr. This version is free to view and download for personal use only. Not for redistribution, re-sale or use in derivative works. ㄷ 2016 Cambridge University Press.
} 


\section{Chapter 1:}

\section{Behaviorist Foundations of the Field of Close Relationships}

Since the early-to-mid-1980's, the subject area of interpersonal relations has undergone a remarkable shift in emphasis within social psychology, from a primary focus on attraction (Berscheid, 1985), to a joint focus on attraction and close relationships (Berscheid \& Reis, 1998), to a primary focus on close relationships (M. S. Clark \& Lemay, 2010). This shift in emphasis within social psychology has coincided with the emergence of a clearly identifiable science of close relationships, which M. S. Clark and Lemay (2010) defined as ongoing human interactions that, over time, serve the functions of “(1) providing both members a sense of security that their welfare has been, and will continue to be protected and enhanced by their [partners'] responsiveness; and (2) providing both members a sense that they, themselves, have been, are, and will continue to be responsive to their partners” (p. 899). Relationship scientists have likened the evolution of their multidisciplinary field to progress through various developmental stages of plants, from "greening” (Berscheid, 1999), to “ripening” (Reis, 2007), to “blossoming” (L. Campbell \& Simpson, 2013).

One of the most highly regarded theories that paved the way for such conceptual and empirical progress in the field of relationship science since the earlyto-mid- 1980s is John Thibaut and Harold Kelley’s (1959; Kelley \& Thibaut, 1978) interdependence theory, which contends that partners in close relationships exert mutual influence upon each other's thoughts, feelings and behavior (Berscheid, 1985). Thibaut and Kelley originally proposed interdependence theory to understand behavioral dynamics within a variety of small groups (Berscheid \& Reis, 1998). However, interdependence theory has proven to be especially useful for 
understanding behavioral dynamics within those small groups that are characterized by close relationships (e.g., friends, romantic couples, families; M. S. Clark \& Lemay, 2010).

Throughout the present book, I shall draw upon Thibaut and Kelley’s (1959; Kelley \& Thibaut, 1978) interdependence theory as an important part of the conceptual and empirical foundation for a science of close relationships. In addition, I shall note the ways in which Kelley and colleagues (e.g., Kelley, 1979; Kelley, Berscheid, Christensen, Harvey, Huston, Levinger, E. McClintock, Peplau, \& Peterson, 1983/2002; Kelley, J. G. Holmes, Kerr, Reis, Rusbult, \& van Lange, 2003) increasingly have acknowledged the extent to which each individual's behavior not only is a consequence and a cause of his or her partner's behavior but also is a consequence (and, possibly, a cause) of the individual's personality (i.e., a variety of within-person characteristics that lie outside the domain of individuals’ presumed cognitive abilities or intelligence; Digman, 1990). By the same token, I shall argue that interdependence theory is necessary -- but not sufficient -- for relationship scientists to understand why individuals behave in a particular manner within close relationships (see also M. S. Clark \& Lemay, 2010).

\section{FUINDAMENTALS OF INTERDEPENDENCE THEORY}

\section{Origins of Thibaut and Kelley's Interdependence Theory: Lewin's Field Theory}

As Kelley and Thibaut (1978) pointed out, their interdependence theory (Thibaut \& Kelley, 1959) originated as an elaboration of Kurt Lewin’s (1936, 1948) field theory. According to field theory, individuals' behavior can be understood as a joint function of factors within persons (i.e., personality and intelligence) and factors outside persons (i.e., aspects of the physical and social environment). In turn, according to interdependence theory, relationship pairs’ or dyads’ pattern of 
interaction can be understood as a joint function of factors within each of the partners and the social situation within which the partners find themselves (Rusbult \& van Lange, 2003).

Both field theory (Lewin, 1936, 1948) and interdependence theory (Kelley \& Thibaut, 1978; Thibaut \& Kelley, 1959) acknowledge the importance of personality in directing each individual's behavior (J. G. Holmes, 2002). However, unlike field theory (which has been embraced by personality psychologists and social psychologists alike; see C. S. Hall \& Lindzey, 1970; Schellenberg, 1978), interdependence theory has been embraced primarily by social psychologists (Berscheid, 1985; Berscheid \& Reis, 1998). Even those social psychologists who have championed the study of personality have tended to cite field theory, rather than interdependence theory, as a major source of conceptual inspiration (e.g., Funder \& Fast, 2010; Snyder \& Cantor, 1998; Snyder \& Ickes, 1985).

Given that interdependence theory (Kelley \& Thibaut, 1978; Thibaut \& Kelley, 1959) is a direct conceptual descendant of field theory (Lewin, 1936, 1948), why did field theory (but not interdependence theory) succeed in capturing the imagination of many personality psychologists? McAdams (1997) noted that Lewin’s conceptualization of needs not only is central to field theory but also is reflected in certain neo-behaviorist personality theories, such as Rotter's (1954) version of social learning theory (which, in turn, gave rise to the personality construct of locus of control; Rotter, 1966). In contrast, although motives or psychological needs can be readily incorporated into interdependence theory (van Lange \& Balliet, 2015), motives (or, for that matter, other major personality constructs) are not as central to interdependence theory as needs are to field theory (see Rusbult \& Arriaga, 2000). Interdependence Theory as a Neo-Behaviorist Social-Psychological Theory 
Throughout his career, Kelley made great efforts to distinguish interdependence theory from (other) behaviorist theories. For example, Kelley and Thibaut (1978, p. 321) criticized Chadwick-Jones (1976) for aligning their interdependence theory (Thibaut \& Kelley, 1959) with Hull’s (1943) version of stimulus-response theory. In addition, Kelley (1979, p. 31) criticized anyone in general (but no one in particular) who might describe interdependence theory as an exchange theory (presumably, albeit not explicitly, in the tradition of Homans's [1961] social exchange theory). Nevertheless, Kelley’s (1979) own definition of interdependence specifically invokes Sears’s (1951) version of stimulus-response theory:

Interdependence refers to the effects [that] interacting persons have on each other. Interdependence can be described in many different ways depending on the nature of the effect in question. Thus we might define interdependence as mutual attitudinal influence, spread of emotional states (contagion), or, as suggested by Robert Sears (1951), mutual behavioral effects, [with] each person's behavior providing the stimulus for the other's response. (p. 13, emphasis in original)

Like other neo-behavorist theories, interdependence theory (Kelley \& Thibaut, 1978; Thibaut \& Kelley, 1959) addresses the role of rewards (i.e., "the positive consequences of interaction”; Rusbult \& Arriaga, 2000, p. 81) versus costs (i.e., "the negative consequences of interaction”; Rusbult \& Arriaga, 2000, p. 81) during the establishment, maintenance, and (potential) termination of close relationships (Berscheid, 1985). However, unlike other behaviorist theories, interdependence theory suggests that many interpersonal situations exist in which individuals understandably refrain from reciprocating partners' rewarding versus costly behavior, 
out of concern that such reciprocation could cause irreparable damage to their relationships (e.g., reciprocating partners' heated anger or criticism; see Agnew \& VanderDrift, 2015). Thus, although it might not be accurate to refer indiscriminately to interdependence theory as one of the "exchange and equity theories” (e.g., Brown, 1986), interdependence theory does share certain important concepts with other neobehaviorist social-psychological theories.

A Case in Point: Rewards and Costs as Reflected in Relationship Commitment

Perhaps the clearest example regarding the importance of rewards and costs to interdependence theory (Kelley \& Thibaut, 1978; Thibaut \& Kelley, 1959) is Caryl Rusbult’s (e.g., Rusbult \& Buunk, 1993; Rusbult, Drigotas, \& Verette, 1994) conceptualization of rewards and costs as direct or indirect antecedents of relationship commitment, or individuals’ conscious decision to remain in a given relationship over the long term (a key construct within interdependence theory; Kelley et al., 1983/2002, 2003). Rusbult (1980, 1983; Rusbult, D. J. Johnson, \& Morrow, 1986a) hypothesized that partners’ rewarding behavior toward individuals would be significant positive predictors of individuals’ commitment. Conversely, Rusbult hypothesized that partners' costly behavior toward individuals would be significant negative predictors of individuals’ commitment.

Consistent with predictions, across several studies, Rusbult (1980, Studies 1 and 2; Rusbult, 1983; Rusbult, D. J. Johnson, \& Morrow, 1986a) found that rewards from partners were significant and positive predictors of individuals' commitment. However, contrary to predictions, Rusbult found that costs from partners were unrelated to individuals' commitment. Nevertheless, Rusbult found that costs from partners were significant and negative predictors of relationship satisfaction, or 
individuals' happiness with their relationships (like commitment, a major construct within interdependence theory; Kelley et al., 1983/2002, 2003).

Despite the importance of rewards and costs to Rusbult’s (1980, 1983;

Rusbult, D. J. Johnson, \& Morrow, 1986a) early studies of satisfaction and commitment, Rusbult eventually became known for her investment model, which focuses on relationship satisfaction, perceived alternatives to the current relationship, and relationship investments as predictors of relationship commitment (for a metaanalytic review, see Le \& Agnew, 2003). Current research on the investment model (which was derived from interdependence theory; Kelly et al., 1983/2002; Kelley et al., 2003) tends not to directly address rewards or costs in close relationships. Indeed, Rusbult’s Investment Model Scale (Rusbult, Martz, \& Agnew, 1998) specifically measures satisfaction, alternatives, investments, and commitment. Therefore, over time, Rusbult and her followers have de-emphasized rewards and costs as explicitly measured interdependence constructs.

This is not to say that rewards and costs have become irrelevant to Rusbult's (1980) investment model. As Rusbult and Arriaga (2000) pointed out, relationship satisfaction is influenced by comparison level (CL), or "the standard by which people evaluate the rewards and costs of a given relationship in terms of what they feel [that] they deserve” (Berscheid, 1985, p. 431). To the extent that individuals’ objective experiences of rewards versus costs meet their subjective internal standard or CL, individuals will tend to be satisfied with their current relationships. Conversely, to the extent that individuals' objective experience of rewards versus costs fail to meet their CL, individuals will tend to be dissatisfied with those relationships. Nevertheless, like objective rewards and costs, individuals' CL is not measured by Rusbult’s Investment Model Scale (Rusbult, Martz, \& Agnew, 1998). 
Another Case in Point: Benefits and Costs as Reflected in Accommodation(?)

Another example regarding the importance of rewards and costs to interdependence theory (Kelley \& Thibaut, 1978; Thibaut \& Kelley, 1959) is Rusbult’s (e.g., Rusbult \& Buunk, 1993; Rusbult, Drigotas, \& Verette, 1994) conceptualization of rewards and (especially) costs as part and parcel of accommodation, or individuals' conscious decision to respond to partners' costly behavior with their own rewarding behavior (yet another major construct within interdependence theory; Kelley et al., 2003). Unlike commitment or satisfaction, accommodation has not been linked empirically - whether directly or indirectly - to rewards or costs per se. Rather, Rusbult and colleagues (Rusbult, Verette, Whitney, Slovik, \& Lipkus, 1991, Studies 1 through 6) began with the assumption that all partners behave badly at times (e.g., express anger and/or criticism toward each other) in close relationships and then asked individuals to indicate how often they have responded to such costly actions with rewarding, relationship-promoting actions versus costly, relationship-threatening actions.

In the process of defining accommodation, Rusbult (e.g., Rusbult \& Buunk, 1993; Rusbult, Drigotas, \& Verette, 1994) distinguished among four potential responses that individuals typically make to relationship partners who have been angry or critical: (1) Exit (a costly and overt response); (2) voice (a rewarding and overt response); (3) loyalty (a rewarding and covert response); and (4) neglect (a costly and covert response). Rusbult and colleagues (1991) contended that, to the extent that individuals refrain from engaging in exit and neglect responses, instead engaging in voice and loyalty responses, individuals display accommodation toward their partners. Indeed, across several studies, Rusbult et al. (1991, Studies 1 through 6) found that relationship commitment was a significant, positive predictor of 
accommodation as operationalized by high voice, high loyalty, low exit, and low neglect.

Given that partners' anger or criticism toward individuals is assumed (rather than measured) in Rusbult's (e.g., Rusbult et al., 1991, Studies 1 through 6) research on accommodation, individuals' transformation of motivation (i.e., "the shift in the way [that] a person understands and interprets the situation”; Arriaga, 2013, p. 46) during accommodative dilemmas must be inferred. Rather than behave in accordance with the norm of reciprocity (which states that individuals are motivated to respond in kind to other persons’ rewarding versus costly behaviors; Gouldner, 1961), individuals who face accommodative dilemmas may decide to put their short-term self-interest aside for the long-term sake of their close relationships (Berscheid \& Reis, 1998).

\section{INTERDEPENDENCE THEORY AND BEYOND: PERSONALITY VARIABLES AS REFLECTED IN CLOSE RELATIONSHIP PROCESSES}

Accommodation as a Consequence of Individual Differences: A Role for Personality Variables within Interdependence Theory

So far, we have considered accommodation (Rusbult et al., 1991) solely as a consequence of one social-psychological variable - namely, individuals’ relationship commitment (Rusbult, 1980, 1983). Such a focus is consistent with Rusbult's belief that all empirical roads within her investment model lead through the interdependence construct of commitment (see Le \& Agnew, 2003). However, Rusbult and colleagues (Rusbult, Olsen, Davis, \& Hannon, 2001) acknowledged that one or more personality variables (as well as additional social-psychological variables) may be reflected directly in accommodation and other "transformation of motivation" processes. 
Citing an article by Kelley (1983) concerning interpersonal dispositions (i.e., aspects of personality that are especially likely to influence individuals' behavior toward relationship partners, at least in principle), Rusbult and van Lange (2003) identified attachment styles (i.e., secure versus insecure orientations toward actual or potential relationship partners in general, presumably arising from the quality of individuals’ earliest experiences with caregivers; Bowlby, 1969/1997, 1973/1998, 1980/1998) as precursors of transformation of motivation processes. At the time that Kelley (1983) was writing about interpersonal dispositions, Hazan and Shaver had not published their breakthrough article (1987) on adult attachment styles. Nevertheless, Rusbult and colleagues (Gaines, Reis, Summer, Rusbult, Cox, Wexler, Marelich, \& Kurland, 1997, Studies 1 through 4) demonstrated that scores on Hazan and Shaver's (1987) original, categorical measure of attachment styles were related significantly to accommodation in heterosexual romantic relationships (i.e., individuals who possessed a secure attachment style scored significantly higher on voice, and significantly lower on exit and neglect, than did individuals who possessed insecure attachment styles).

Furthermore, citing Kelley (1983), Rusbult and van Lange (2003) identified social value orientations (i.e., cooperative versus non-cooperative preferences for outcomes in interdependence situations; C. G. McClintock, 1978) as precursors of transformation of motivation processes. Social value orientations have not been examined as predictors of accommodation in close relationships. However, van Lange and colleagues (van Lange, Otten, de Bruin, \& Joireman, 1997. Studies 1 and 2) found that individuals who held a cooperative preference scored significantly higher on secure attachment style (measured as a continuous variable, adapted from Hazan \& Shaver, 1987) than did individuals who held non-cooperative preferences - 
a finding that could pave the way for future research on (secure) attachment style as a mediator of the impact of social value orientations on accommodation.

Two important caveats are worth keeping in mind regarding van Lange et al.’s (1997) conceptualization of social value orientations as interpersonal dispositions.

First, personality psychologists tend to view cultural value orientations (i.e., organized sets of beliefs that are communicated by various societal agents to individuals; Hofstede, 1980), rather than social value orientations (McClintock, 1978), as personality constructs (see also Kwan \& Herrmann, 2015). Second, even if personality psychologists were to adopt the view that social value orientations qualify as personality constructs, attachment theorists in particular (following Bowlby, 1969/1997, 1973/1998, 1980/1998) probably would argue that social value orientations should be considered as outcomes -- rather than predictors -- of attachment styles (see Landau \& D. Sullivan, 2015). We will return to the construct of social value orientations in Chapter 4.

Bowlby’s Attachment Theory: A Personality Theory that Potentially Complements Thibaut and Kelley's Interdependence Theory

If Thibaut and Kelley’s (1959; Kelley \& Thibaut, 1978) interdependence theory is the preeminent behaviorist theory within the field of relationship science (Arriaga, 2013), then John Bowlby’s (1969/1997, 1973/1998, 1980/1998) attachment theory - which is based on the premise that human beings (among other species) need emotional intimacy with other persons, from infancy onward - is the preeminent personality theory within this field (Mikulincer \& Shaver, 2013). Hazan and Shaver (1994a) advocated an integration of interdependence and attachment perspectives within the field of relationship science. Indeed, results of the aforementioned studies by Rusbult and colleagues (Gaines, Reis, et al., 1997) suggest that attachment theory 
can complement interdependence theory regarding insight into such "transformation of motivation” processes as accommodation (see also Gaines, Granrose, Rios, Garcia, Page, Farris, \& Bledsoe, 1999; Gaines \& Henderson, 2002).

First, let us consider the given situation, or "the benefits and costs that objectively exist, as determined by basic structural characteristics, which reflect a person's preferences without any concerns for the interaction partner” (Arriaga, 2013, p. 46), that individuals face when their relationship partners express anger or criticism toward them. Interdependence theory (Kelley \& Thibaut, 1978; Thibaut \& Kelley, 1959) is silent regarding the issue of master motives (see Rusbult \& van Lange, 2003). However, attachment theory (Bowlby, 1969/1997, 1973/1998, 1980/1998) suggests that all individuals are motivated to seek emotional intimacy with other persons, even when other persons behave badly toward them (Hazan \& Shaver, 1994a). Although a "pure” interdependence analysis might focus primarily on the costs that individuals experience when they are on the receiving end of anger or criticism from their significant others, a combined interdependence and attachment analysis might focus as much upon the benefits that being with their partners might offer, as upon the costs that bearing the brunt of partners' negativity might yield.

Next, let us consider the effective situation, or "the benefits and costs that direct behavior, which are revised from outcomes in a given situation, and reflect preferences based on broader social considerations” (Arriaga, 2013, p. 46). Interdependence theory (Kelley \& Thibaut, 1978; Thibaut \& Kelley, 1959) does refer broadly to interpersonal dispositions as influences on the "transformation of motivation" that causes individuals to shift from the given situation to the effective situation (Kelley, 1983) but generally has not offered a systematic basis for identifying specific interpersonal dispositions that might influence accommodation 
(see Rusbult \& van Lange, 2003). In contrast, attachment theory (Bowlby, 1969/1997, 1973/1998, 1980/1998) indicates that although most (i.e., securely attached) individuals find it relatively easy to trust relationship partners (largely due to their earliest caregivers' consistent giving of love and affection), many (i.e., insecurely attached) individuals find it relatively difficult to trust relationship partners (largely to their earliest caregivers' inconsistent or non-existent giving of love and affection; Hazan \& Shaver, 1994a). Although a “pure” interdependence analysis might focus primarily on securely attached individuals’ capacity, alongside insecurely attached individuals’ incapacity, for maintaining their relationships (and, thus, rewarding partners in spite of partners’ negativity), a combined interdependence and attachment analysis might focus as much upon securely attached individuals’ greater tendency to appreciate and to respond to partners' past rewarding behavior, as upon securely attached individuals’ greater tendency to avoid responding to partners’ present costly behavior.

\section{Attachment Styles: Holding their Own against Commitment in Predicting}

\section{Accommodation}

As noted earlier, Rusbult (e.g., Rusbult et al., 1991, Studies 1 through 6) consistently emphasized the social-psychological construct of commitment as a predictor of accommodation. However, several of Rusbult's own studies (e.g., Gaines, Reis, et al., 1997, Studies 1 through 4) indicate that - whether operationalized as categorical or continuous variables (Hazan \& Shaver, 1987) - the personality constructs of secure, anxious-ambivalent, and avoidant attachment styles are significantly related to accommodation. Given the status of commitment as a “relationship-specific motive” (Rusbult \& van Lange, 2003, p. 368) that presumably operates alongside interpersonal dispositions in predicting "transformation of 
motivation” processes such as accommodation, one might ask whether commitment and attachment styles each explain unique variance when they are entered together as predictors of accommodation.

In one study, Rusbult and colleagues (Wieselquist, Rusbult, Foster, \& Agnew, 1999, Study 2) examined commitment as well as continuous measures of secure, anxious-ambivalent, and avoidant attachment styles (Hazan \& Shaver, 1987) as predictors of accommodation in heterosexual relationships. The data from the study in question previously formed the empirical foundation for Study 4 of the aforementioned research by Gaines, Reis, et al. (1997). Wieselquist et al. (1999) found that commitment was a significant, positive predictor; anxious-ambivalent attachment style was a significant, negative predictor; and secure attachment style was a marginal, positive predictor of accommodation (avoidant attachment style was unrelated to accommodation).

Based on the results of Rusbult and colleagues (Wieselquist et al., 1999), it appears that attachment styles hold their own when they are entered alongside commitment as predictors of accommodation. However, Rusbult and colleagues concluded that “self-reported attachment style does not account for substantial variance beyond the features of interdependence that [collectively] form the basis for the present model” (Wieselquist et al., 1999, p, 942). This apparent paradox can be solved once one realizes that accommodation was the only "transformation of motivation” process that Rusbult and colleagues considered among a host of dependent variables (i.e., dependence level, commitment, accommodation, partners’ perceived partner accommodation, trust, and partners' trust); attachment styles fared better in predicting accommodation than in predicting the other interdependence constructs (see Gaines \& Agnew, 2003). 
Beyond Attachment Theory: A Broader Perspective on Personality and Accommodation in Close Relationships

Hazan and Shaver (1994a) made a compelling case for incorporating attachment theory (Bowlby, 1969/1997, 1973/1998, 1980/1998) throughout the field of relationship science. Nevertheless, Hazan and Shaver (1994b) also acknowledged that - like any scientific theory - attachment theory possesses limitations as well as strengths. For example, attachment theorists' increasing emphasis on mental representations of self and other (i.e., individuals’ positive versus negative internal working models of themselves and of relationship partners in general; Bartholomew, 1990) as consciously experienced relationship schemata (see Berscheid, 1994) has inadvertently led to a gap in relationship scientists' knowledge regarding the role of the unconscious in attachment processes (Berscheid, 2010). This gap in knowledge is especially ironic in light of the psychodynamic origins of attachment theory (Mikulincer \& Shaver, 2007).

Several classic “social-psychological” theories of personality (following C. S. Hall \& Lindzey, 1970) offer relationship scientists the opportunity to broaden their conceptual and methodological horizons beyond attachment theory (Bowlby, 1969/1997, 1973/1998, 1980/1998) as they explore interpersonal dispositions as influences on “transformation of motivation” processes such as accommodation. Perhaps the most obvious theoretical candidate for such exploration is Harry Stack Sullivan's (1953) interpersonal theory, which contends that individuals' personalities cannot be properly understood without reference to the social and personal relationships within which individuals operate (Gaines, 2007a, b). Some interdependence theorists (e.g., Kelley, 1983) have implicitly drawn upon interpersonal theory, whereas some attachment theorists (e.g., Bartholomew, 1990) 
have explicitly drawn upon interpersonal theory, in identifying those aspects of personality that are especially likely to be reflected in close relationship processes. Furthermore, if one accepts the premise of interpersonal theorist Jerry Wiggins (1991) that the gender-role orientation of positive femininity (i.e., a tendency to behave in a manner that benefits other persons, stereotypically associated with women; Bem, 1974 ) is equivalent to the interpersonal trait of nurturance (which, in turn, is individuals' self-descriptive manifestation of the human condition that is known as communion), then Rusbult et al.’s (1991, Studies 3, 4, and 5) finding that positive femininity is a significant, positive predictor of accommodation can be interpreted as support for interpersonal theory as a complement to interdependence theory.

So far, we have considered personality constructs that were derived from specific personality theories. However, many personality constructs either have been developed without regard to theory or, in effect, function as stand-ins for entire theories. For instance, the cultural value construct of individualism versus collectivism (Hofstede, 1980) arguably does not qualify as a theory in itself (Gaines, 1997); yet the constructs of individualism and collectivism clearly have influenced cross-cultural research on cultural value orientations and accommodation (whereby interpersonal value orientation was a significant positive predictor, and personal value orientation was a significant negative predictor, of accommodation; Gaines \& Ramkissoon, 2008). Thus, personality influences on "transformation of motivation” processes such as accommodation need not be linked to specific personality theories. Beyond Accommodation: Relational Trust as a Consequence of Personality Influences

Thus far, we have focused on accommodation, to the exclusion of other interdependence constructs as consequences of personality constructs. However, in 
the aforementioned study of commitment, attachment styles, and accommodation in heterosexual romantic relationships by Rusbult and colleagues (Wieselquist et al., 1999, Study 2), anxious-ambivalent attachment style (Hazan \& Shaver, 1987) emerged as a significant, positive predictor of relational trust (i.e., "feelings of confidence and security in the caring responses of the partner and the strength of the relationship”; Rempel, J. G. Holmes, \& Zanna, 1985, p. 96), the latter of which is as fundamental to interdependence theory (Kelley \& Thibaut, 1978; Thibaut \& Kelley, 1959) as is commitment or accommodation (Kelley et al., 2003). Relational trust includes three components: (1) Predictability (i.e., the extent to which individuals believe that their partners' past behavior is indicative of partners' present and future behavior; (2) dependability (i.e., the extent to which individuals believe that they understand their partners’ personalities, based on partners’ past and present behavior; and (3) faith (i.e., the extent to which individuals believe that their relationships will persist, in spite of possible uncertainty and challenges over time).

Rusbult and van Lange (2003) positioned relational trust (and, for that matter, commitment) as a "relationship-specific motive” (p. 368) that functions alongside interpersonal dispositions as predictors of “transformation of motivation” processes. However, one could argue relational trust itself is a "transformation of motivation" process (or, at a minimum, entails “transformation of motivation”; Simpson, 2007) that reflects individuals' willingness to risk rejection, even rejection, by their partners (see W. H. Jones, Couch, \& Scott, 1997). In turn, if relational trust is an example of individuals' "transformation of motivation," then it should come as no surprise that in the aforementioned study by Rusbult and colleagues (Wieselquist et al., 1999, Study 2), at least one attachment style (i.e., anxious-ambivalent) emerged as a significant 
predictor of relational trust, after perceived partner accommodation was taken into account (see Murray \& J. G. Holmes, 2009).

Consistent with the aforementioned finding (Wieselquist et al., 1999, Study 2) that anxious-ambivalent attachment style (Hazan \& Shaver, 1987) significantly predicted relational trust (Rempel \& J. G. Holmes, 1986), Rusbult and colleagues (Gaines, Panter, Lyde, Steers, Rusbult, Cox, \& Wexler, 1997, Study 2) found that the interpersonal traits of dominance (i.e., individuals' tendency to behave in ways that benefit themselves) and nurturance (i.e., individuals' tendency to behave in ways that benefit other persons; Wiggins, Trapnell, \& Phillips, 1988) were significant, positive predictors of relational trust in heterosexual romantic relationships. The data in question had formed the foundation for Study 1 of Gaines, Panter, et al.’s (1997) research on attachment styles and accommodation. The results regarding dominance as a significant predictor of relational trust are especially noteworthy when one considers that dominance - which Wiggins (1991) viewed as equivalent to the genderrole orientation of positive masculinity (i.e., individuals' tendency to behave in their self-interest, stereotypically associated with men; Bem, 1974) - is not consistently related to individuals’ behavior in close relationships; see Ickes, 1985; Snyder \& Ickes, 1985).

One caveat regarding the scope of relational trust: Although Rempel, J. G. Holmes, and Zanna (1985) originally emphasized similarities between their construct of relational trust and Rotter’s (1967) earlier construct of interpersonal trust, Wrightsman (1991) pointed out that interpersonal trust as conceptualized by Rotter is individuals’ positive attitude toward human nature in general; whereas relational trust as conceptualized by Rempel, J. G. Holmes, and Zanna is individuals’ positive attitude toward relationship partners in particular. Also, relational trust as 
conceptualized by Rempel, J. G. Holmes, and Zanna clearly involves individuals’ formation of attributions regarding partners' personalities and behavior (J. G. Holmes, 2004) - a social-cognitive process that is not linked clearly to interpersonal trust as conceptualized by Rotter (see also J. G. Holmes, 2002). Finally, relational trust as conceptualized by Rempel, J. G. Holmes, and Zanna fits squarely within the evolving view (Kelley, 1997b) that interdependence theory (Kelley \& Thibaut, 1978; Thibaut \& Kelley, 1959) is as much a theory of cognition as it is a theory of behavior (see Kelley, 1997a) - a view that might help explain why relationship scientists have tended to gravitate away from Rotter's social-learning construct of generalized trust (see Simpson, 2007).

Beyond “Transformation of Motivation” Processes: Interdependence Processes in General as Manifestations of Individuals’ Personalities(?)

Throughout the present chapter, we have examined accommodation (Rusbult et al., 1991) as influenced by the personalities of individuals within close relationships. Given that Caryl Rusbult was known first and foremost as a social psychologist and not as a personality psychologist (Reis, A. Aron, M. S. Clark, J. G. Holmes, \& van Lange, 2010), it might seem ironic that several of Rusbult's published empirical papers (e.g., Gaines, Panter, et al., 1997; Gaines, Reis, et al., 1997; Rusbult et al., 1991; Wieselquist et al., 1999) directly addressed the impact of personality on accommodation and other "transformation of motivation" processes. Then again, no less an authority on personality than attachment theorist Phillip Shaver (2010) cited Rusbult's conceptualization and measurement of accommodation as one of the most enduring aspects of Rusbult's legacy to the field of close relationships.

The conceptual rationale and accompanying evidence concerning personality influences on individuals' behavior in close relationships may be stronger for 
“transformation of motivation” processes such as accommodation (Rusbult et al., 1991) than is the case for other interdependence processes. For example, A. Aron and E. N. Aron (2010) contended that self-expansion (i.e., the process of including significant others in individuals’ self-conceptions; A. Aron \& E. N. Aron, 1986) - a process that Agnew, van Lange, Rusbult, and Langston (1998) likened to cognitive interdependence - might preclude “transformation of motivation” processes under certain conditions in close relationships. Indeed, results of a study by Dalsky, Gohm, Noguchi, and Shiomura (2008) indicate that the cultural value of collectivism (Yamaguchi, 1994) is a significant, positive predictor of including other in the self (A. Aron, E. N. Aron, \& Smollan, 1992) across samples in the United States and Japan. Nevertheless, compared to personality influences on "transformation of motivation" processes such as accommodation, the role of personality in self-expansion has received relatively little attention within the literature on close relationships (see Gaines \& Ketay, 2013).

Of course, interdependence theory (Kelley \& Thibaut, 1978; Thibaut \& Kelley, 1959) is not the only behaviorist theory that one might employ to investigate the effects of personality variables on close relationship processes (M. S. Clark \& Lemay, 2010). Nevertheless, the field of relationship science historically has neglected the systematic study of personality influences (M. S. Clark \& Reis, 1988); and interdependence theory is well-positioned to assist relationship scientists in identifying those behavioral processes that are particularly likely to reflect the impact of personality (Rusbult \& van Lange, 2003).

\section{OVERVIEW OF THE PRESENT BOOK}

The present Chapter 1 serves as an introduction to close relationships, from the perspective of the dominant neo-behaviorist theory within the field of relationship 
science (i.e., interdependence theory; Kelley \& Thibaut, 1978; Thibaut \& Kelley, 1959). Following the present chapter, we shall explore the impact of the self in general on relationship processes in Chapter 2. Afterward, we shall consider five major personality constructs (i.e., traits, Chapter 3; values, Chapter 4; attitudes, Chapter 5; motives, Chapter 6; and emotions, Chapter 7) that might be reflected in close relationship processes. Finally, we shall conclude the present book by critiquing our review of the literature and identifying potential directions for future research in Chapter 8. 